\title{
La Revista Forestal del Perú
}

\author{
Marc J. Dourojeanni Ricordi ${ }^{1}$
}

Hasta 1967 el Perú no dispuso de una publicación científica o técnica especializada en asuntos forestales. Hubo apenas un antecedente breve, entre 1960 y 1962, con la publicación de dos números del Boletín Forestal que era el órgano de la desaparecida Asociación Forestal del Perú. Los artículos científicos o técnicos y asimismo los divulgativos referidos al sector forestal, que dicho sea de paso eran muy escasos, se publicaban en diversas revistas del sector agrario.

En 1963, por iniciativa del Rector, Orlando Olcese Pachas y del Director del Servicio Forestal y de Caza, Flavio Bazán Peralta, fue creada la Facultad de Ciencias Forestales de la Universidad Agraria. Para eso se dispuso del apoyo de la Organización de las Naciones Unidas para la Agricultura y la Alimentación (FAO) y del Programa de las Naciones Unidas para el Desarrollo (PNUD), mediante el Proyecto FAO/ PNUD PER 20 de "Capacitación e Investigación Forestal en el Perú". Este proyecto fue financiado por el PNUD y tuvo un costo inicial de 918.000 dólares. Comenzó el 19 de noviembre de 1963 y tuvo una duración prevista de cinco años. El proyecto tenía tres objetivos centrales: (i) implantar y desarrollar la Facultad de Ciencias Forestales de la Universidad Agraria, (ii) establecer un instituto de investigaciones forestales $y$, (iii) organizar una escuela de peritos forestales en Iquitos.
El Instituto de Investigaciones Forestales se creó mediante convenio entre la Universidad Agraria y el Servicio Forestal y de Caza y empezó a funcionar en 1964 en el local de la Facultad, en La Molina. Su personal estaba conformado por un equipo nuclear de funcionarios del Servicio Forestal y de profesores de la Facultad pero, en realidad, incluía todo el personal profesional de ambas instituciones, dependiendo de su participación en las líneas de investigación. Estas eran básicamente cuatro que correspondían a los cuatro departamentos del Instituto: (i) Manejo Forestal, (ii) Productos Forestales, (iii) Protección y Conservación y, (iv) Política y Economía Forestal. Entre 1965 y 1968 estos departamentos estuvieron respectivamente a cargo de Adolfo Salazar, Antonio Aróstegui, Marc Dourojeanni y Emilio David. Estos coordinaban tanto las actividades de investigación de la Universidad como las del Servicio Forestal y las de los expertos de la FAO que habían todos sido reconocidos como profesores visitantes de la Universidad. En ese lapso la presidencia del Instituto la tuvo Flavio Bazán mientras que la dirección estuvo a cargo de Fernando Galván y luego de Adolfo Salazar. El Instituto contó, para sus primeros años, de un Comité Coordinador presidido por Flavio Bazán e integrado por Eduardo Izquierdo, ambos representando al Servicio Forestal y por Adolfo Salazar y Antonio Aróstegui que representaban a la Universidad Agraria.

\footnotetext{
${ }^{1}$ Ingeniero Agrónomo, Ingeniero Forestal, Doctor en Ciencias. Profesor Emérito de la Universidad Nacional Agraria La Molina, Perú. E-mail: marc.dourojeanni@gmail.com
} 
Como es obvio, desde el comienzo estuvo previsto que el Instituto dispusiera de una revista propia para difundir los resultados de sus investigaciones y estudios, especialmente considerando el hecho de que no existía ninguna otra en el Perú que pudiese acogerlos de forma adecuada. El Comité Editor de la revista estuvo integrado inicialmente por Consuelo Bazán de Segura y por Elmo Montenegro, quien era profesor visitante de la FAO. En los años siguientes se produjeron varios cambios en el Comité Editor que incluyó asimismo, entre otros, a Marino González, Rafael Lao, Raúl González, René Campos, Augusto Tovar, Antonio Brack y Carlos Vereau. A mediados de los años 1970 los dos últimos representaban a la Dirección General Forestal y de Fauna, que contribuía a su financiamiento. La idea inicial de la revista, que fue bautizada como Revista Forestal del Perú, fue reunir en ella artículos originales tanto de tipo científico como tecnológicos. Estaba previsto publicar un volumen anual con uno o más números, en función del material disponible. Las normas editoriales incluían la aplicación de las usadas por la Organización Internacional de Investigaciones Forestales (IUFRO). Pero en algunos periodos la revista también acogió artículos de opinión o discusión sobre temas relevantes así como informaciones más generales y hasta noticias del sector.

El primer número de la Revista apareció en marzo de 1967, siendo presentado por un editorial firmado por Flavio Bazán. En ese núme- ro se divulgaron los estatutos de la Revista y las normas para la preparación de artículos. Correspondió a este autor el honor de haber escrito el primer artículo del primer número del primer volumen de la Revista. En él se describía el primer registro para el Perú de una plaga del eucalipto originaria de Australia. En ese mismo número también había artículos firmados por Consuelo Bazán de Segura, John Yavorski, Antonio Aróstegui y Alberto Sato; Per Christensen, William Guerra, y por Emilio David y Seymour Somberg.

No puede negarse que a partir de los años 1970 pero especialmente en las décadas subsiguientes hubo cierto descuido en la tarea de publicar la revista. En efecto, por ejemplo ya en 1976 el atraso era considerable siendo publicado el volumen 6 cuándo ya debía estarse publicando el volumen 9. La situación se agravó mucho con el tiempo y al momento de cumplir su primer cincuentenario la Revista cuenta con 32 volúmenes en lugar de 50. Además fueron pocos los volúmenes que ofrecieron más de un número. La justificación principal para esa situación fue la falta de presupuesto para la publicación. Eso se debió en parte a que el Instituto de Investigaciones Forestales fue desactivado en 1969 con la extinción del Servicio Forestal y de Caza. Y, aunque la nueva Dirección General Forestal y de Fauna continuó considerando la Revista Forestal del Perú como órgano de difusión compartido con la Universidad Agraria, sus aportes para su publicación fueron dis-

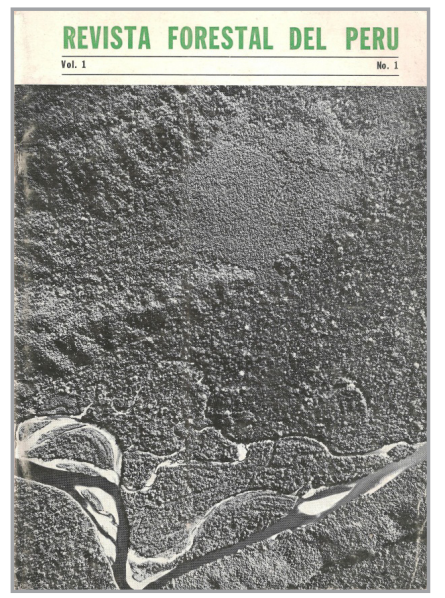

Figura 2.

Carátula del primer número de la Revista Forestal del Perú (1967). 
minuyendo y desaparecieron completamente en los difíciles años 1980. Sin embargo, entre 1987 y 1993 nuevamente se publicaron continuamente dos números por cada volumen, con artículos de muy buena calidad. Es decir que la falta de fondos no justifica el hecho, tanto más que el número de investigaciones y estudios continuó aumentando, lamentablemente sin encontrar medios para su difusión. Ocurre que una revista científica, especialmente en el Perú, depende mucho del entusiasmo de su editor jefe que debe luchar no sólo por recibir buenos artículos sometidos a tiempo sino que, asimismo, debe perseguir el financiamiento de cada número. Es una tarea que requiere de mucho esfuerzo y que recibe poca o ninguna recompensa. Por eso hay periodos en que nadie asume seriamente esa función.

La revista Xilema, órgano de los estudiantes de la Facultad de Ciencias Forestales de la Universidad Nacional Agraria La Molina, que nació en 1982, fue la alternativa para la publicación de numerosos trabajos de investigación y de opinión tanto de estudiantes como de profesores. Xilema ya produjo 30 volúmenes $\mathrm{y}$, además, es reconocida internacionalmente y posee versión electrónica. Los jóvenes mostraron el camino a sus mayores. Y, recordando la historia del alma mater, es preciso decir que Xilema tuvo un precedente. En efecto, por más de tres décadas la única publicación seriada de la Escuela Nacional de Agricultura y de la Universidad Agraria fue la revista Agronomía, que era editada por la Federación de Estudiantes. Lamentablemente, desapareció a poco de ser lanzada la revista Anales Científicos, órgano oficial de la Universidad. Xilema debe mantenerse por siempre lado a lado con la Revista Forestal del Perú.

De cualquier modo, en esta primera etapa la Revista Forestal del Perú ha cumplido con su tarea de reunir y perennizar más de 300 artículos preparados por más de 550 autores, que han contribuido de manera decisiva al acervo científico y tecnológico forestal del país. Sin la Revista, esos trabajos serían desconocidos y por tanto inútiles. En efecto, hasta los años 1990 los informes originales que generaron los artículos eran difundidos en muy pocos ejem- plares publicados con mimeógrafo, tornándose frecuentemente ilegibles después de algunos años. La Revista Forestal del Perú, en cambio, ha sido enteramente escaneada y desde su primer número está disponible en la Internet.

En estos tiempos de renovación las autoridades de la Facultad de Ciencias Forestales han decidido, muy acertadamente, relanzar la Revista Forestal del Perú pero con un alto padrón de calidad y modernidad, como lo planearon sus fundadores cincuenta años atrás y, asimismo, se han comprometido a asegurar la continuidad y regularidad de la publicación, lo que es trascendental. En representación de los fundadores de la Revista este autor aplaude la iniciativa y desea que tenga el mejor de los éxitos en su propósito, que como antes y ahora pretende contribuir efectivamente al desarrollo del sector forestal peruano.

Presentado: 17/04/2017 Aceptado: 18/04/2017 